\title{
Modeling interaction between distribution company and networked microgrids in optimal operation of active distribution network
}

\author{
Himan Hamedi*, Vahid Talavat***, Ali Tofighi*** and Reza Ghanizadeh* \\ * Department of Electrical Engineering, Urmia Branch, Islamic Azad University, Urmia, Iran \\ ** Department of Electrical Engineering, Urmia University, Urmia, Iran \\ *** Department of Electrical Engineering, Pardis Branch, Islamic Azad University, Pardis, Iran \\ ** Corresponding Author: V.Talavat@urmia.ac.ir
}

Submitted : 16/12/2019

Revised : :10/08/2021

Accepted :22/08/2021

\begin{abstract}
In this paper, the interaction between energy sellers and buyers in utilizing active distribution networks is modeled with considering two networked and nonnetworked modes of microgrids (MGs). A retail electricity market is modeled as a bilevel problem. Accordingly, the Distribution Company (DISCO) in the upper level in order to maximize the profit offers an optimal price to MGs, while in the lower level, the MGs are used to compare the offered prices by DISCO with the prices of MGs generation sources for minimizing the total costs decided to whether to buy from the DISCO or not. The first contribution of the paper is to consider the networked operation of the MGs under a unique beneficiary of MGs (BMG). As the second contribution, two extremely important indices, that is, reserve and self-adequacy, are considered, which are necessary in the problems related to MGs. In this paper, the impact of considering and disregarding these two important indices of MGs, that is, reserve and self-adequacy, on the profit of the DISCO in two different scenarios is investigated. In each scenario, the impact of considering two modes of MGs, that is, networked and nonnetworked, on the profit of DISCO is investigated. Simulation results show the efficiency of the presented model.
\end{abstract}

Keywords: Active distribution network; Microgrid; Networked operation; Retail market; Reserve and selfadequacy.

\section{INTRODUCTION}

From technical perspective, a MG is a system consisting of DG units and loads, which can be utilized in gridconnected or stand-alone modes. In active distribution networks, usually, there are several MGs that can be utilized independently or in coordination with each other. These MGs always interact with the Distribution Company (DISCO) (Khodaei et al., 2013). In active distribution networks, making a decision about operation of MGs is a bilevel process. The DISCO is in the upper level of decision making, and MGs are in its lower level. To utilize the system at the optimum point, optimization problems for each of these two levels must be solved independently and 
in coordination with each other. Therefore, the optimization problem will be a bilevel problem, in which the DISCO wants to maximize its profit, and the MGs want to minimize their costs. Therefore, decisions made in each of these levels will affect the decision-making process of the other one.

In Rieger et al. (2016), the authors investigate the advantages of cooperation in residential MGs. The objective functions used in this research are fuel consumption costs and demanded peak energy cost. In Umeozor ea al. (2016), the authors address the operational scheduling of MGs via parametric programming. Zhang, J. et al. (2016) propose a new algorithm to solve simultaneously the day-ahead scheduling problem of MGs and unit commitment problem, considering the power flow constraints in transmission network as well as the normal and urgent conditions of the network. In Karimzadeh et al. (2019), the load of the MGs has been implemented using the exchanges between the MGs, and the cost of utilization and power supply of the loads minimized. In Fathi (2017), in fact, the distribution grid is not modeled. In Zhang, $\mathrm{H}$ et al. (2015), the economic utilization of a MG is independent from that of a distribution network; MGs do not have a unique beneficiary, and they do not have any access to the resources of each other in critical conditions. Bahramara et al. $(2015 ; 2016)$ deal with the problem of utilizing an active distribution network in the presence of MGs. In these references, the trade space between DISCO and MGs is modeled. In this problem, the DISCO seeks to maximize its profit, and the MGs want to minimize their costs. This problem is considered a bilevel problem and solved. The operations of the MGs and DISCO are studied using a system-ofsystems framework (Kargarian et al., 2014).

In Zamora et al. (2018), a multilayer architecture is designed to control the networked MGs. This architecture is aimed at controlling the magnitude of voltage, frequency, and output power of DGs in the networked MGs. In Hussain et al. (2018), an energy management strategy is presented for day-ahead scheduling of networked MGs. Simulation results show that the operation costs of the networked MGs are decreased by using this approach. In Nikmehr et al. (2017), two programs of time-based demand response and real-time pricing are considered to increase the efficiency of solving the problem of interest. The operation of hybrid networked MGs is studied in Hussain et al. (2017). To solve the optimization problems, deterministic (Avirup et al., 2017) and stochastic (Wang, 2015) algorithms have been used in the mentioned studies. In Lei et al. (2013), MG agents have dual role who can either buy electricity directly from the wholesale market at volatile prices or sell electricity to the market or to its local consumers.

In this paper, the interaction between energy sellers and buyers in utilizing active distribution networks with considering networked MGs is modeled. The objective of the distribution network, as the upper-level problem, is to maximize its profit, and the objective of the networked MGs, as the lower-level problem, is to minimize the costs. Therefore, this paper contains a bilevel problem, which is solved using the genetic algorithm. In this paper, MGs consist of DGs and load curtailment, which are used by the beneficiary of the networked MGs to minimize the costs. The first contribution of this paper is the consideration of networked operation of MGs in the problem of interaction between the DISCO and MGs. Networked operation of MGs means that all MGs interact with the DISCO under a unique management. In other words, all MGs are under the control of the beneficiary of MGs (BMG) to provide the energy required by the MGs. As the second contribution, the networked MG needs to provide the required reserve and self-adequacy features. By the term reserve, we mean that the beneficiary of MGs must always supply an amount of energy more than the amount required by the MGs, so that they can supply the energy required by the MGs when emergency conditions are encountered or when an error exists in forecasting the renewable energy generation. Furthermore, the self-adequacy feature means that, at least, a certain percentage of MG loads must be supplied by the resources of the MG itself. In other words, MG must be able to supply its essential loads by its own resources. 


\section{PROBLEM FORMULATION}

As mentioned earlier, the purpose of this paper is to model the trade structure between the DISCO and networked MGs (Fig 1). The DISCO seeks to maximize its profit as the upper level (leader) of this structure. The DSICO can gain profit in two ways: first, by purchasing energy from a wholesale market and selling it to the MGs, and second, by purchasing energy from MGs and selling it to the wholesale market as demand response programs. In the networked mode of MGs, the BMG is at the lower level of the problem (follower), which has access to the resources of each of the MGs to supply the need of power the set of MGs. Its objective is to minimize the costs of supplying the energy required by the networked MGs, which is done in this case by using the resources available to the MGs (generation resources and load curtailment) and by purchasing from the DISCO. The bilevel structure of the interaction between the BMG and DISCO (leader-follower decision making) is shown in Fig 2. As can be clearly seen in this figure, in the upper level, the DISCO offers its energy selling price to the BMG. In addition, in the lower level, the BMG, by considering the price of energy supplied by its own resources, decides to buy or sell energy to the DISCO. When the price offered by the DISCO is changed, the BMG will also change the amount of buying/selling energy from/to the DISCO. This continues until the profit of the BMG is maximized. In the proposed genetic algorithm, first, the problem data including specifications of generation units and MGs loads and the prices of wholesale market are recorded. Then, the initial population of the genetic algorithm, which contains the prices offered by the DISCO to the BMG, is randomly generated. When these prices are offered to the BMG, this beneficiary decides either to supply the energy required by the MGs by its own resources or to purchase it from the DISCO. If this beneficiary has surplus energy generation with an appropriate cost, it will sell the energy to the DISCO. Once the amount of trade between the DISCO and networked MGs is determined, the profit of the DISCO will be calculated for each individual of the population, and half of the individuals that result in higher profit will be selected as superior individuals. Then, mutation and crossover operators will be applied to these individuals, and new individuals will be generated. The number of these individuals will be half the size of the initial population. If the algorithm reaches the last iteration, the best individual (the one with the highest amount of profit for DISCO) is selected as the optimum individual, and the profit of the DISCO and the costs of networked MGs will be calculated. Otherwise, new prices are offered to the BMG, and the process will continue until the last iteration.

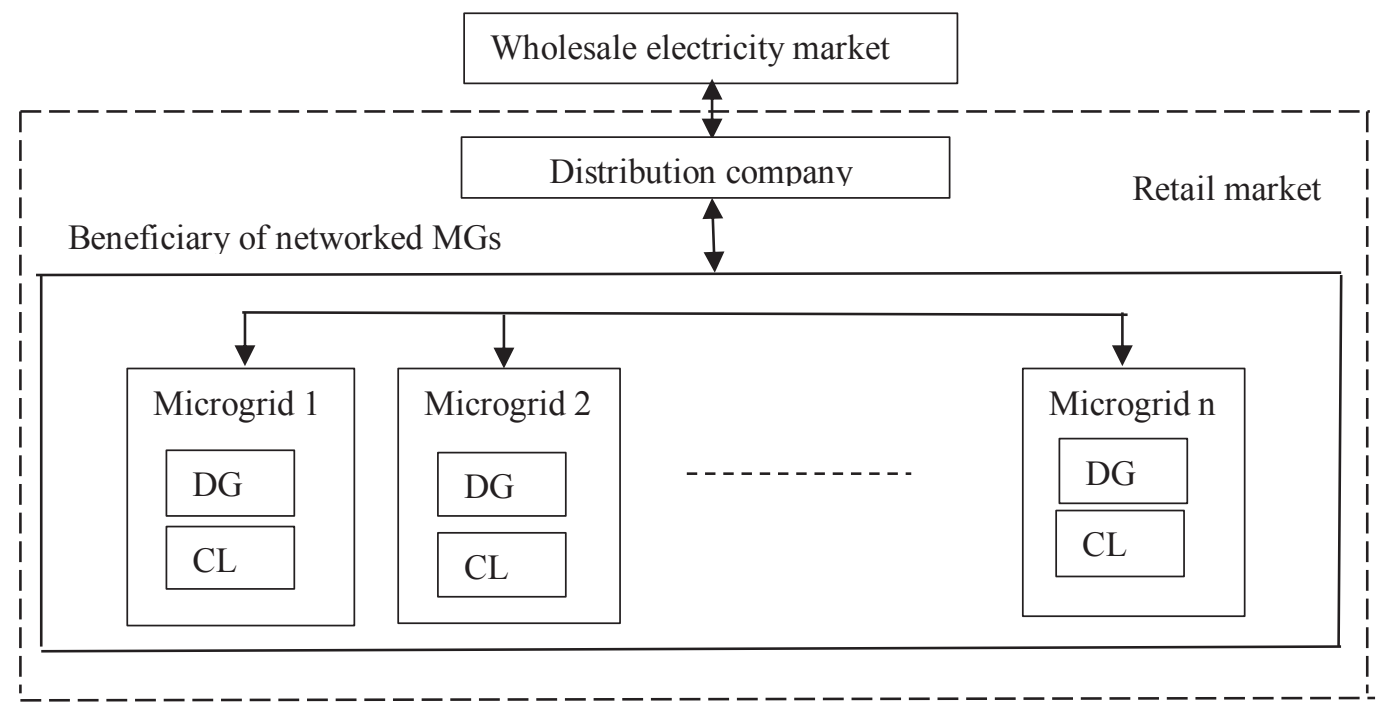

Figure 1. Retail market in distribution network level. 


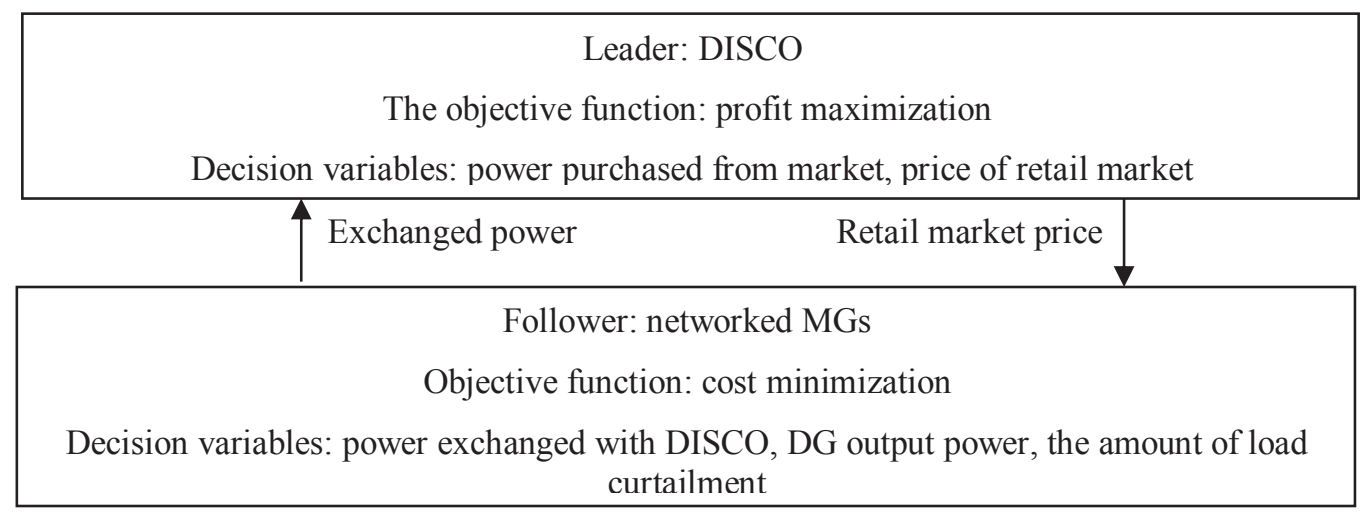

Figure 2. Bilevel decision-making structure in the problem of trading energy between the DISCO and the networked MGs.

In the upper level, the problem of DISCO is presented in Equation (1). In this equation, the objective is to maximize the profit of the DISCO gained from purchasing energy from the wholesale market and selling it to the networked MGs. In this equation, if $\mathrm{P}_{\mathrm{D}}>0$, the DISCO has sold energy to the networked MGs, and if $\mathrm{P}_{\mathrm{D}}<0$, the DISCO has bought power from the networked MGs. If $\mathrm{P}_{\mathrm{D}}=0$, no power is exchanged between the DISCO and the mentioned MGs.

$$
\max _{\substack{\rho_{D}, P_{D}, P_{D} \\ P^{M}, P_{D}}} \sum_{j}\left(\rho_{D} \cdot P_{D}\right)-\rho^{M} \cdot P^{M}
$$

The parameters of Equation (1) are given in Equations (2)-(4):

$$
\begin{aligned}
& 0 \leq \rho_{D} \leq \rho^{\max } \\
& P^{M} \leq P_{\max }^{T_{u p}} \\
& P_{D}=P^{M}
\end{aligned}
$$

where $\rho_{D}$ is the price of power exchanged between the DISCO and networked MGs ( $\left.\$ / \mathrm{MW} \mathrm{h}\right), P_{D}$ the power exchanged between the DISCO and networked MGs ( $\$$ MW h), $\rho^{M}$ the price in the wholesale market ( $\left.\$ / \mathrm{MW} \mathrm{h}\right), P^{M}$ the power exchanged between the DISCO and market (MW), $P_{D G}$ the power generated by DGs resources in the networked MGs (MW), $P_{I L}$ the amount of load curtailment in networked MGs (MW), $\rho_{\max }$ the maximum limit for price of power exchanged between the DISCO and networked MGs $(\$ / \mathrm{MW} \mathrm{h}), P_{\max }^{u p}$ the maximum limit for the power purchased by the DISCO from the power market (MW), and j counter the number of MGs. 
Equation (2) expresses the range of offering price between the DISCO and networked MGs. The range of the power, which can be bought from the wholesale market, can also be explained by Equation (3). The power balance constraint of the DISCO is expressed in Equation (4). This constraint shows that the power exchanged with the networked MGs is equal to the power bought from the power market.

The problem of the lower level, which is the problem of the networked MGs, is expressed in Equation (5). This problem includes the cost of the power exchanged with the DISCO, the cost of generating power by the DGs, and the costs of load curtailment. Equation (6) shows the range of power that can be exchanged between the networked MGs and DISCO. Constraint Equation (7) expresses the range of output power of DGs in each MG. Constraint Equation (8) shows the amount of load curtailment in each MG. Equation (9) shows the power balance constraint in the networked MGs. This equation shows that, in the networked MGs, the sum of the power exchanged with the DISCO, the interrupted load, and the power generated by the DGs is equal to the amount of energy consumption and reserve. The self-adequacy features are expressed in Equation (10). Equations (11)-(12) show the relationship between the generation of the DGs and load curtailment of the networked MGs. In this problem, considering the price offered by the DISCO, the networked MGs have minimized their costs. The parameters of Equation (5) are defined in Equations (6)-(12).

$$
\begin{aligned}
& \min _{P_{D}, P_{I L}, P_{D G}} \rho_{D} \cdot P_{D}+C_{D G} \cdot P_{D G}+C_{I L} \cdot P_{I L} \\
& -P_{\max }^{T} \leq P_{D} \leq P_{\max }^{T} \\
& P_{D G, \min }^{j} \leq P_{D G}^{j} \leq P_{D G, \max }^{j} \\
& 0 \leq P_{I L}^{j} \leq P_{I L, \text { max }}^{j} \\
& P_{D G}+P_{D}+P_{I L}=P_{\text {demand }}+P_{\text {reserve }} \\
& P_{D G}+P_{I L} \geq \alpha . P_{\text {demand }} \\
& P_{D G}=\sum_{j=1}^{n} P_{D G}^{j} \\
& P_{I L}=\sum_{j=1}^{n} P_{I L}^{j}
\end{aligned}
$$

where $C_{D G}$ is the generation cost of the DGs in the networked MGs ( $\left.\$ / \mathrm{MW} \mathrm{h}\right), C_{I L}$ the cost of load curtailment in the networked MGs (\$/MW h), $P_{\max }^{T}$ the maximum limit for the power exchanged between the DISCO and networked MGs (MW), $P_{D G \text {,max }}^{j}$ the maximum limit of the capacity of DGs source in the $\mathrm{MG}_{\mathrm{j}}(\mathrm{MW}), P_{D G, \min }^{j}$ the 
minimum limit of the capacity of DGs in the $\mathrm{MG}_{\mathrm{j}}(\mathrm{MW}), P_{I L, \text { max }}^{j}$ the maximum limit of load curtailment in the $\mathrm{MG}_{\mathrm{j}}$ (MW), $P_{\text {demand }}$ the amount of energy or load consumption in the networked MGs (MW), $P_{\text {reserve }}$ the amount of energy reserve required by the networked MGs (MW), and $\alpha$ the certain percentage of the load in order to consider the self-adequacy feature in the networked MGs.

\section{SIMULATION RESULTS}

This paper seeks to develop a model for the trade space between DISCO and MGs. Accordingly, in the upper level, the DISCO tries to maximize its profit by purchasing electricity from the power market and selling it to the networked MGs. Therefore, in order to maximize its profit, DISCO offers a price to the BMG. On the other side, in the lower level, the BMG, by comparing three items, the price offered by the DISCO, the load curtailment costs, and the costs of distributed generation units of the MGs, will obtain an optimum combination to supply its required power. Therefore, the networked MGs try to minimize their costs. In the nonnetworked mode, the MGs are not able to use low-cost resources of other MGs, while this is possible in the networked mode. Simulations will be carried out with and without considering the reserve and self-adequacy indices of MGs. In each scenario, to evaluate the impact of the networked operation of MGs, the results of the simulations of the networked operation mode of MGs will be compared to the results of the nonnetworked operation mode of them.

In this paper, simulations are performed in two main scenarios:

- First scenario: simulation of the trade between DISCO and MGs without considering the reserve and selfadequacy indices of the MGs in the two networked and nonnetworked modes.

- Second scenario: simulation of the trade between DISCO and MGs with considering the reserve and selfadequacy indices of the MGs in the two networked and nonnetworked modes.

Moreover, each of these scenarios will be simulated for the variations of energy price in the wholesale market. The range of electricity price in the wholesale market is considered to be between 35 and $46 \$ / \mathrm{MW}$ h. Therefore, each scenario will contain 12 simulations making a total number of 24 simulations. MGs can interrupt $10 \%$ of their own load as the load curtailment resource. The cost of load curtailment by the MGs is considered to be $41 \$ / \mathrm{MW} \mathrm{h}$. The maximum price offered by the DISCO to each MG is $50 \$ / M W h$. In this paper, 4 MGs with different values are studied, and the data related to them is presented in Table 1[15].

Table 1. Specifications of MGs.

\begin{tabular}{|c|c|c|c|c|}
\hline MGs No. & $\begin{array}{c}\text { Minimum power of } \\
\text { DGs (MW) }\end{array}$ & $\begin{array}{c}\text { Maximum power of } \\
\text { DGs (MW) }\end{array}$ & $\begin{array}{c}\text { Generation cost } \\
(\$ / \mathrm{MW})\end{array}$ & Load (MW) \\
\hline 1 & 0 & 4 & 37 & 5 \\
\hline 2 & 0 & 5 & 40 & 5 \\
\hline 3 & 0 & 5.5 & 45 & 6 \\
\hline 4 & 0 & 7 & 45 \\
\hline
\end{tabular}

The simulation results are presented in the following subsection. 


\section{FIRST SCENARIO}

The trade between DISCO and MGs is simulated in two modes of MGs, that is, networked and nonnetworked, without considering the reserve and self-adequacy indices of the MGs. The results of the first scenario in nonnetworked mode of MGs are presented in Table 2. The proposed algorithm at any market price, regarding the operation cost of the internal resources of the MGs and also the amount of power demand required by MGs, calculates and proposes an optimum price to DISCO for sale energy to MGs.

Table 2. Results of the first scenario in nonnetworked mode of MGs.

\begin{tabular}{|c|c|c|c|c|c|c|c|c|c|}
\hline $\begin{array}{l}\text { Market } \\
\text { price } \\
(\$ / \mathrm{MWh})\end{array}$ & $\begin{array}{c}\text { price } \\
\text { offered by } \\
\text { DISCO } \\
(\$ / \mathrm{MW} \mathrm{h})\end{array}$ & $\begin{array}{l}\mathrm{P}_{\mathrm{DG} 1} \\
(\mathrm{MW})\end{array}$ & $\begin{array}{c}\mathrm{P}_{\mathrm{DG} 2} \\
(\mathrm{MW})\end{array}$ & $\begin{array}{l}\mathrm{P}_{\mathrm{DG} 3} \\
(\mathrm{MW})\end{array}$ & $\begin{array}{c}\mathrm{P}_{\mathrm{DG} 4} \\
(\mathrm{MW})\end{array}$ & $\begin{array}{c}\mathrm{P}_{\mathrm{IL}} \\
(\mathrm{MW})\end{array}$ & $\begin{array}{c}\mathrm{P}_{\mathrm{D}} \\
(\mathrm{MW})\end{array}$ & $\begin{array}{l}\text { MGs cost } \\
\text { (\$/MW h) }\end{array}$ & $\begin{array}{c}\text { DISCO } \\
\text { profit } \\
(\$ / \mathrm{MW} \mathrm{h})\end{array}$ \\
\hline 35 & 39.98 & 4 & 0 & 5.5 & 0 & 0 & 12 & 820.66 & 59.76 \\
\hline 36 & 44.96 & 4 & 5 & 5.5 & 0 & 1.55 & 5.45 & 849.11 & 48.86 \\
\hline 37 & 44.96 & 4 & 5 & 5.5 & 0 & 1.55 & 5.45 & 849.11 & 43.41 \\
\hline 38 & 44.96 & 4 & 5 & 5.5 & 0 & 1.55 & 5.45 & 849.11 & 37.96 \\
\hline 39 & 44.96 & 4 & 5 & 5.5 & 0 & 1.55 & 5.45 & 849.11 & 32.51 \\
\hline 40 & 44.96 & 4 & 5 & 5.5 & 0 & 1.55 & 5.45 & 849.11 & 27.06 \\
\hline 41 & 44.96 & 4 & 5 & 5.5 & 0 & 1.55 & 5.45 & 849.11 & 21.61 \\
\hline 42 & 44.96 & 4 & 5 & 5.5 & 0 & 2.15 & 4.85 & 846.73 & 14.38 \\
\hline 43 & 44.96 & 4 & 5 & 5.5 & 0 & 2.15 & 4.85 & 846.73 & 9.53 \\
\hline 44 & 44.96 & 4 & 5 & 5.5 & 0 & 2.15 & 4.85 & 846.73 & 4.68 \\
\hline 45 & - & 4 & 5 & 5.5 & 4.85 & 2.15 & 0 & 846.90 & 0 \\
\hline 46 & 45.01 & 4 & 5 & 5.5 & 7 & 2.15 & -2.15 & 846.86 & 2.11 \\
\hline
\end{tabular}

The results of the first scenario in networked mode of MGs are presented in Table 3. It should be noted that it is not important whether all or some of the MGs participate in supplying the load. Therefore, in the networked operation mode of MGs, in fact, all MGs are considered as an integrated MG.

Table 3. Results of the first scenario in networked mode of MGs. 


\begin{tabular}{|c|c|c|c|c|c|c|c|c|c|}
\hline $\begin{array}{c}\text { Market } \\
\text { price } \\
(\$ / \mathrm{MWh})\end{array}$ & $\begin{array}{c}\text { Price } \\
\text { offered by } \\
\text { DISCO } \\
(\$ / \mathrm{MWh})\end{array}$ & $\begin{array}{c}\mathrm{P}_{\mathrm{DG} 1} \\
(\mathrm{MW})\end{array}$ & $\begin{array}{c}\mathrm{P}_{\mathrm{DG} 2} \\
(\mathrm{MW})\end{array}$ & $\begin{array}{c}\mathrm{P}_{\mathrm{DG} 3} \\
(\mathrm{MW})\end{array}$ & $\begin{array}{c}\mathrm{P}_{\mathrm{DG} 4} \\
(\mathrm{MW})\end{array}$ & $\begin{array}{c}\mathrm{P}_{\mathrm{IL}} \\
(\mathrm{MW})\end{array}$ & $\begin{array}{c}\mathrm{P}_{\mathrm{D}} \\
(\mathrm{MW})\end{array}$ & $\begin{array}{l}\text { MGs cost } \\
\text { (\$/MWh) }\end{array}$ & $\begin{array}{c}\text { DISCO } \\
\text { profit } \\
(\$ / \mathrm{MWh})\end{array}$ \\
\hline 35 & 39.98 & 4 & 0 & 5.5 & 0 & 0 & 12 & 820.66 & 59.76 \\
\hline 36 & 39.98 & 4 & 0 & 5.5 & 0 & 0 & 12 & 820.26 & 47.76 \\
\hline 37 & 44.96 & 4 & 5 & 5.5 & 0 & 2.15 & 4.85 & 846.73 & 38.63 \\
\hline 38 & 44.96 & 4 & 5 & 5.5 & 0 & 2.15 & 4.85 & 846.73 & 33.78 \\
\hline 39 & 44.96 & 4 & 5 & 5.5 & 0 & 2.15 & 4.85 & 846.73 & 28.93 \\
\hline 40 & 44.96 & 4 & 5 & 5.5 & 0 & 2.15 & 4.85 & 846.73 & 24.08 \\
\hline 41 & 44.96 & 4 & 5 & 5.5 & 0 & 2.15 & 4.85 & 846.73 & 19.23 \\
\hline 42 & 44.96 & 4 & 5 & 5.5 & 0 & 2.15 & 4.85 & 846.73 & 14.38 \\
\hline 43 & 44.96 & 4 & 5 & 5.5 & 0 & 2.15 & 4.85 & 846.73 & 9.53 \\
\hline 44 & 44.96 & 4 & 5 & 5.5 & 0 & 2.15 & 4.85 & 846.73 & 4.68 \\
\hline 45 & - & 4 & 5 & 5.5 & 4.85 & 2.15 & 0 & 846.90 & 0 \\
\hline 46 & 45.01 & 4 & 5 & 5.5 & 7 & 2.15 & -2.15 & 846.86 & 2.11 \\
\hline
\end{tabular}

The impact of the market price and the amount of power exchanged between the DISCO and MGs on the profit of DISCO are visible. With increasing the market price, the costs of MGs gradually increased. With increasing the market price, the profit of the DISCO has decreased, because resources, which are available to the MGs, are cheaper than the prices offered by DISCO to them.

In the wholesale market prices 35 \$MW $\mathrm{h}$ in two networked and nonnetworked modes of MGs, the price agreed upon between the MGs and DISCO is 39.98 \$ MW h. As is clear in this table, at first, the power generation resources of MGs 1 and 3 have been used because these two resources have the lowest prices. Having used these two resources, MGs purchased the remainder of their required energy from the DISCO, which is equal to $12 \mathrm{MW}$. The DGs of MGs 2 and 4 and also load curtailment resources have not been used because they have higher prices.

In the market prices 36 \$MW h, the amount of power purchased from the DISCO by MGs in nonnetworked mode of MGs is $5.45 \mathrm{MW}$, and also it is $12 \mathrm{MW}$ in the networked mode. The profit of DISCO in the networked mode of MGs decreased compared to that of the nonnetworked mode. Although DISCO sold more power, the price 
accepted by the MGs is lower in this case. On the other hand, since the networked MGs provide their required power from cheaper resources, their costs have been reduced.

For the market price 37 \$ MW h in the networked mode of MGs, the price agreed upon between the networked MGs and DISCO is $44.96 \$ / \mathrm{MW}$. It should be noted that if the price offered by the DISCO, as in the previous case, was $39.98 \$ / \mathrm{MW} \mathrm{h}$, the MGs would purchase $12 \mathrm{MW}$ of power from DISCO, instead of 4.85 MW. However, due to a lower accepted price by MGs, the profit of the DISCO would be $35.76 \$ / \mathrm{MW} \mathrm{h}$. It should be noticed that the profit of DISCO would be lower than this value if the offered price was $44.96 \$ / \mathrm{MW}$. This is why the DISCO decided to offer this price to the MGs for achieving the maximum profit. The DISCO continued this process until the wholesale market price became 44 \$/MW.

For the market price $45 \$ / M W h$ in two modes of MGs, the MGs provided the required energy entirely from their resources, and it did not buy any power from the DISCO. Additionally, because of the high cost of purchasing energy from the wholesale market, the DISCO does not offer any price to the MGs, and its profit is 0 . For the market price $46 \$ / M W h$ in both modes of MGs, this time, the DICO purchase power is from the MGs because its price is lower than the market price.

In the networked mode, since the MGs have access to resources with lower prices than the power price offered by the DISCO, they can purchase less power from the DISCO and take advantage of the inexpensive capacity of some MGs to supply their required power instead. Due to this case, at most wholesale prices, the costs of networked MGs have decreased compared to the nonnetworked modes. Besides, the profit of the DISCO has been reduced. By comparing the above tables, we can reach the results shown in Figures 3 and 4.

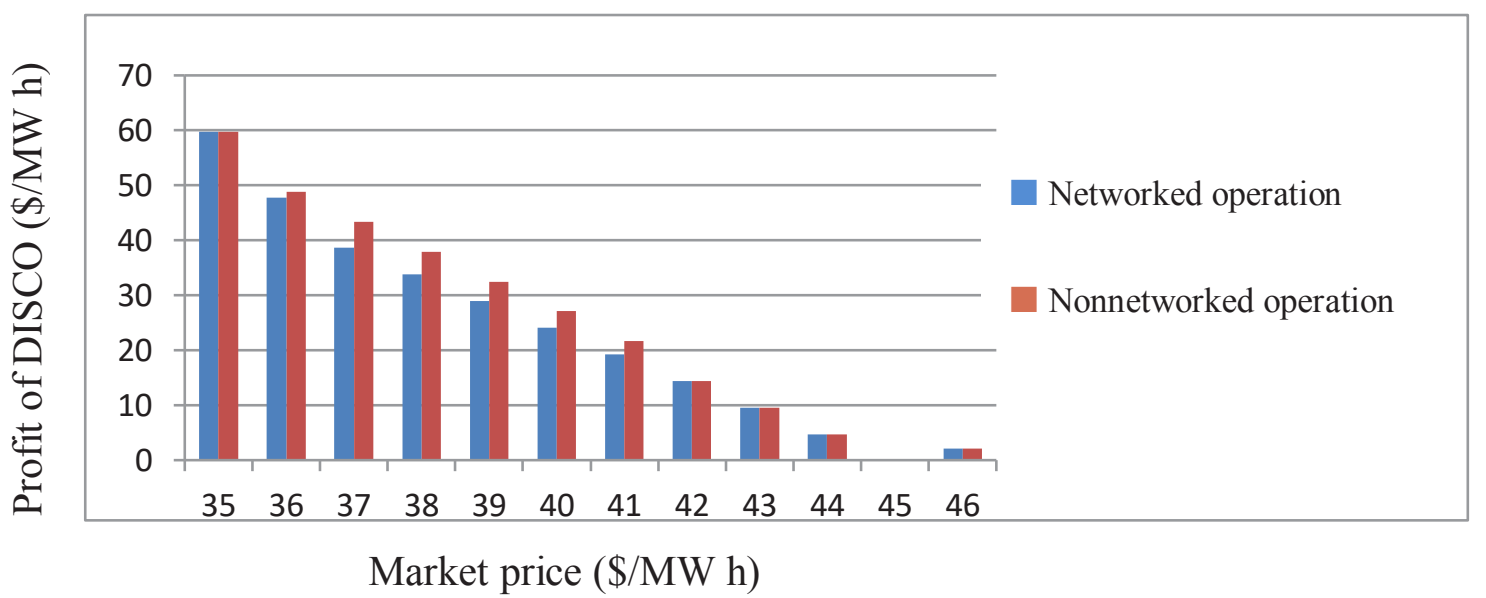

Figure 3. Profit of DISCO in networked and nonnetworked operation modes of MGs. 


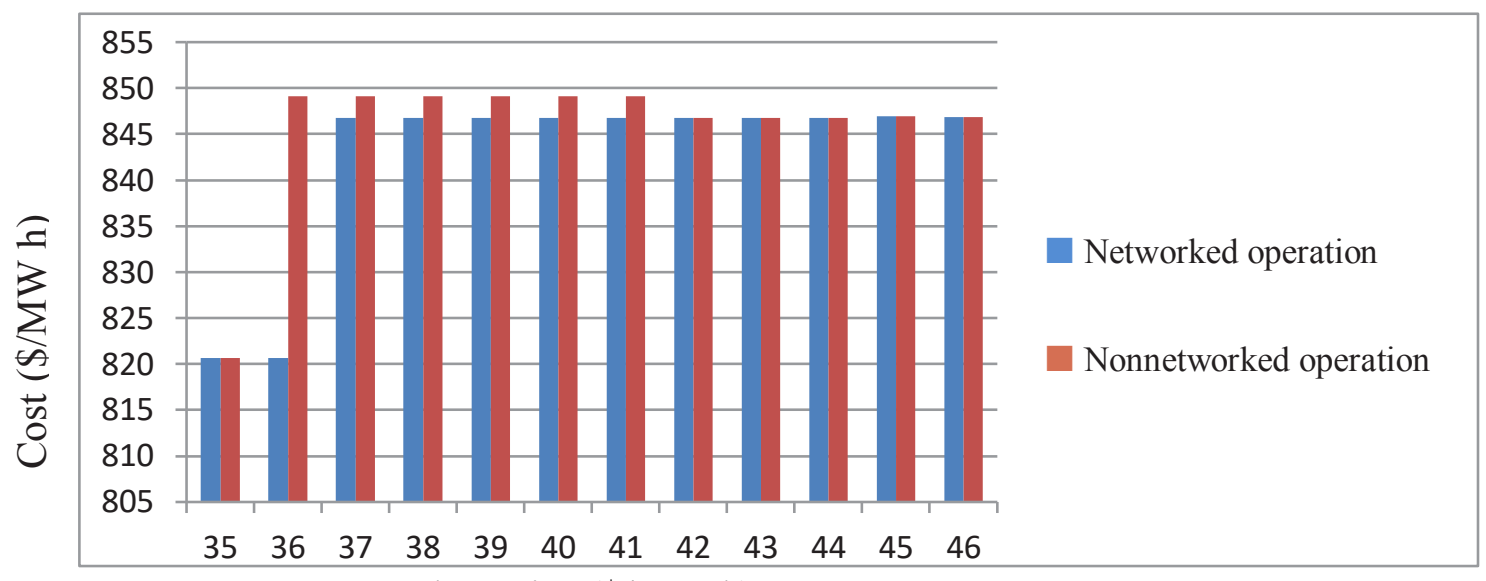

Market price (\$/MW h)

Figure 4. Cost of MGs in networked and nonnetworked operation modes of MGs.

\section{SECOND SCENARIO}

In this subsection, the trade between the DISCO and MGs with considering reserve and self-adequacy indices of the MGs is simulated in two modes of MGs, that is, networked and nonnetworked. The results of the nonnetworked mode of MGs are presented in Table 4.

MGs should be able to supply their required energy in the event of emergency situations or due to a percentage error in forecasting the production of renewables sources. Also, MGs must also be able to supply their required essential loads from their own resources. For this purpose, it is extremely important to consider the reserve and selfsufficiency indices in the operation of the MGs because it makes them safe in critical conditions. In the nonnetworked mode of MGs, each one of MGs is able to consider 10 percent of its power as reserve index. Moreover, every MG should provide 60 percent of the power it needs by its own resources as self-adequacy index. According to the simulations, the profit of the DISCO and the cost of the nonnetworked MGs with considering the reserve and selfadequacy indices are presented in Table 4.

Table 4. Results of the second scenario in nonnetworked mode of MGs.

\begin{tabular}{|c|c|c|c|c|c|c|c|c|c|}
\hline $\begin{array}{c}\text { Market } \\
\text { price } \\
(\$ / \mathrm{MWh})\end{array}$ & $\begin{array}{c}\text { Price } \\
\text { offered } \\
\text { by } \\
\text { DISCO } \\
(\$ / \mathrm{MWh})\end{array}$ & $\begin{array}{c}\mathrm{P}_{\mathrm{DG} 1} \\
(\mathrm{MW})\end{array}$ & $\begin{array}{c}\mathrm{P}_{\mathrm{DG} 2} \\
(\mathrm{MW})\end{array}$ & $\begin{array}{c}\mathrm{P}_{\mathrm{DG} 3} \\
(\mathrm{MW})\end{array}$ & $\begin{array}{c}\mathrm{P}_{\mathrm{DG} 4} \\
(\mathrm{MW})\end{array}$ & $\begin{array}{c}\mathrm{P}_{\mathrm{IL}} \\
(\mathrm{MW})\end{array}$ & $\begin{array}{c}\mathrm{P}_{\mathrm{D}} \\
(\mathrm{MW})\end{array}$ & $\begin{array}{c}\text { MGs cost } \\
(\$ / \mathrm{MWh})\end{array}$ & $\begin{array}{c}\text { DISCO } \\
\text { profit } \\
(\$ / \mathrm{MWh})\end{array}$ \\
\hline 35 & 44.96 & 4 & 5 & 5.5 & 2.75 & 2.15 & 4.25 & 943.49 & 42.35 \\
\hline 36 & 44.96 & 4 & 5 & 5.5 & 2.75 & 2.15 & 4.25 & 943.49 & 38.10 \\
\hline 37 & 44.96 & 4 & 5 & 5.5 & 2.75 & 2.15 & 4.25 & 943.49 & 33.85 \\
\hline
\end{tabular}




\begin{tabular}{|c|c|c|c|c|c|c|c|c|c|}
\hline 38 & 44.96 & 4 & 5 & 5.5 & 2.75 & 2.15 & 4.25 & 943.49 & 29.60 \\
\hline 39 & 44.96 & 4 & 5 & 5.5 & 2.75 & 2.15 & 4.25 & 943.49 & 25.35 \\
\hline 40 & 44.96 & 4 & 5 & 5.5 & 2.75 & 2.15 & 4.25 & 943.49 & 21.10 \\
\hline 41 & 44.96 & 4 & 5 & 5.5 & 2.75 & 2.15 & 4.25 & 943.49 & 16.85 \\
\hline 42 & 44.96 & 4 & 5 & 5.5 & 2.75 & 2.15 & 4.25 & 943.49 & 12.60 \\
\hline 43 & 50 & 4 & 5 & 5.5 & 5.5 & 2.15 & 1.5 & 951.15 & 10.50 \\
\hline 44 & 50 & 4 & 5 & 5.5 & 5.5 & 2.15 & 1.5 & 951.15 & 9 \\
\hline 45 & 50 & 4 & 5 & 5.5 & 5.5 & 2.15 & 1.5 & 951.15 & 7.5 \\
\hline 46 & 46.96 & 4 & 5 & 5.5 & 7 & 2.15 & 0 & 943.63 & 0 \\
\hline
\end{tabular}

In networked mode of MGs, all MGs that are under unique management are able to consider 10 percent of their total power as reserve index. Moreover, the networked MGs should provide 60 percent of the total power they need by their own resources as self-adequacy index. It should be noted that it is not important that all MGs contribute to provide this percentage of self-adequacy or only a portion of them. Therefore, in the networked mode of operation of the MGs, virtually, all the MGs were considered under a unique beneficiary. Basically, after supplying a specific part of the power required from MGs own internal resources, BMG had to buy the rest of required power from the DISCO at an even higher price. According to the simulations, the profit of the DISCO and the cost of the networked MGs with considering the reserve and self-adequacy indices are presented in Table 5.

Table 5. Results of the second scenario in networked mode of MGs.

\begin{tabular}{|c|c|c|c|c|c|c|c|c|c|}
\hline $\begin{array}{c}\text { Market } \\
\text { price } \\
(\$ / \mathrm{MWh})\end{array}$ & $\begin{array}{c}\text { Price } \\
\text { offered } \\
\text { by } \\
\text { DISCO } \\
(\$ / \mathrm{MWh})\end{array}$ & $\begin{array}{c}\mathrm{P}_{\mathrm{DG} 1} \\
(\mathrm{MW})\end{array}$ & $\begin{array}{c}\mathrm{P}_{\mathrm{DG} 2} \\
(\mathrm{MW})\end{array}$ & $\begin{array}{c}\mathrm{P}_{\mathrm{DG} 3} \\
(\mathrm{MW})\end{array}$ & $\begin{array}{c}\mathrm{P}_{\mathrm{DG} 4} \\
(\mathrm{MW})\end{array}$ & $\begin{array}{c}\mathrm{P}_{\mathrm{IL}} \\
(\mathrm{MW})\end{array}$ & $\begin{array}{c}\mathrm{P}_{\mathrm{D}} \\
(\mathrm{MW})\end{array}$ & $\begin{array}{c}\text { MGs } \\
\text { cost } \\
(\$ / \mathrm{MWh})\end{array}$ & $\begin{array}{c}\text { DISCO } \\
\text { profit } \\
(\$ / \mathrm{MWh})\end{array}$ \\
\hline 35 & 44.96 & 4 & 5 & 5.5 & 0 & 2.15 & 7 & 943.41 & 69.71 \\
\hline 36 & 44.96 & 4 & 5 & 5.5 & 0 & 2.15 & 7 & 943.41 & 62.85 \\
\hline 37 & 44.96 & 4 & 5 & 5.5 & 0 & 2.15 & 7 & 943.41 & 55.52 \\
\hline 38 & 44.96 & 4 & 5 & 5.5 & 0 & 2.15 & 7 & 943.41 & 48.35 \\
\hline 39 & 44.96 & 4 & 5 & 5.5 & 0 & 2.15 & 7 & 943.41 & 41.75 \\
\hline 40 & 44.96 & 4 & 5 & 5.5 & 0 & 2.15 & 7 & 943.41 & 34.22 \\
\hline
\end{tabular}




\begin{tabular}{|c|c|c|c|c|c|c|c|c|c|}
\hline 41 & 44.96 & 4 & 5 & 5.5 & 0 & 2.15 & 7 & 943.41 & 27.45 \\
\hline 42 & 44.96 & 4 & 5 & 5.5 & 0 & 2.15 & 7 & 943.41 & 20.92 \\
\hline 43 & 44.96 & 4 & 5 & 5.5 & 0 & 2.15 & 7 & 943.41 & 13.81 \\
\hline 44 & - & 4 & 5 & 5.5 & 0 & 2.15 & 7 & 943.41 & 6.72 \\
\hline 45 & - & 4 & 5 & 5.5 & 7 & 2.15 & 0 & 943.63 & 0 \\
\hline 46 & 44.96 & 4 & 5 & 5.5 & 7 & 2.15 & 0 & 943.63 & 0 \\
\hline
\end{tabular}

By comparing Tables 4 and 5, it can be concluded that the profit of DISCO in networked operation mode of MGs increased compared to the profit of DISCO in the nonnetworked mode of MGs except at market prices of 44 and $45 \$ / M W h$. The profit of DISCO reduced compared to the nonnetworked mode of MGs just in these two market prices. Since, in the nonnetworked operation mode of MGs, they do not have access to each other's resources, accordingly, they have to buy a portion of their required power from DISCO at a very high price. The results are shown in Fig 5.

With considering the reserve and self-adequacy indices of the MGs, the total cost of the MGs at the most market prices in the networked mode of MGs is almost constant compared to the nonnetworked mode and even reduced in some market Prices. The reason for this is that, in order to supply the power required by MGs with more expensive resources, BMG use MGs with cheaper resources. In fact, MGs being networked helped them not increase their cost compared to the nonnetworked mode, despite having two useful indices, that is, the reserve and self-adequacy. The results are shown in Fig 6.

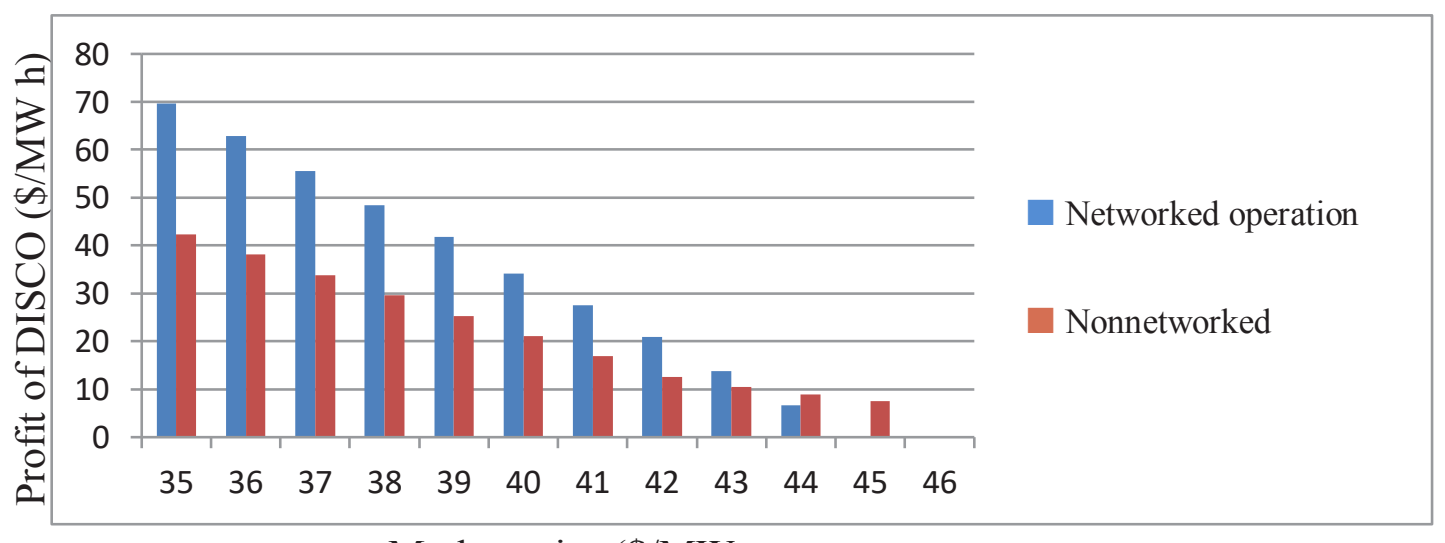

Market price $(\$ / \mathrm{MW}$

Figure 5. Profit of DISCO in networked and nonnetworked operation modes of MGs with considering reserve and self-adequacy. 


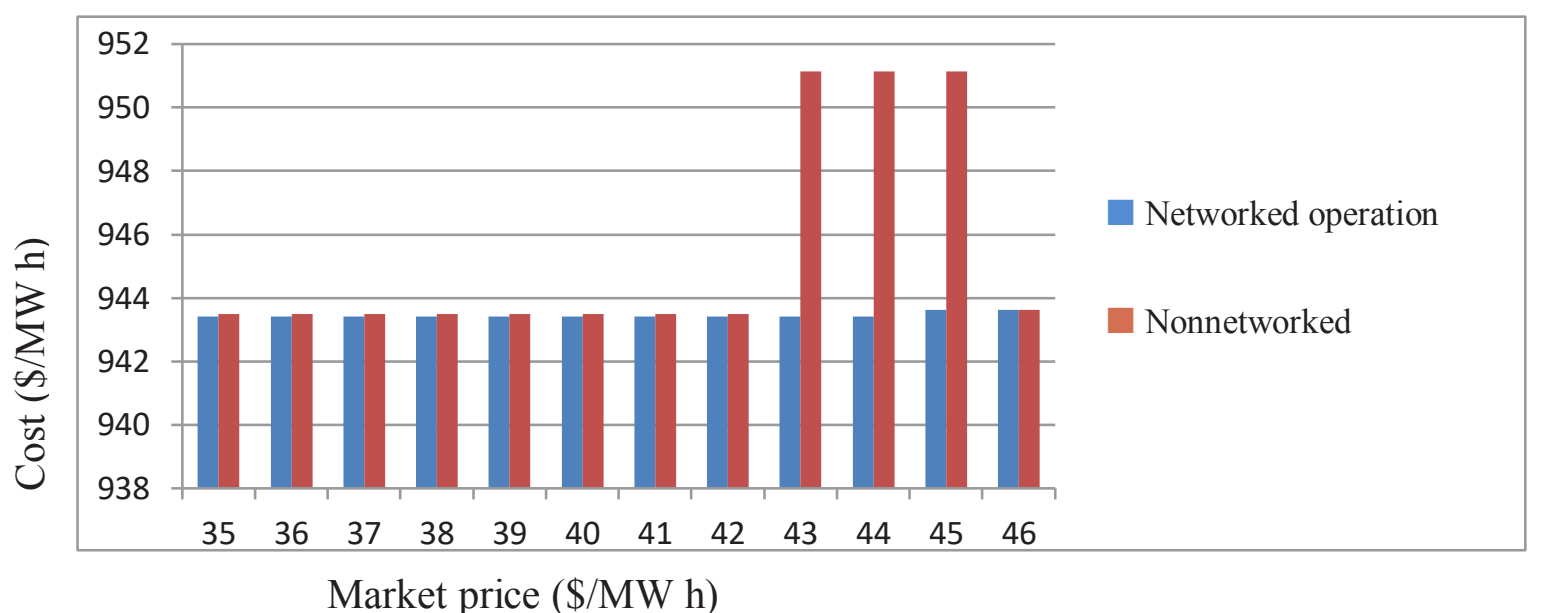

Figure 6. Costs of MGs in networked and nonnetworked operation modes of MGs with considering reserve and self-adequacy.

\section{CONCLUSION}

In this paper, a retail electricity market is modeled between DISCO and the MGs as a bilevel problem. The DISCO, in the upper level, in order to maximize the profit, offered an optimal price to the BMG, while in the lower level, the BMG compared the offered prices with the prices of MGs generation sources for minimizing the total costs and deciding whether to buy from the DISCO or not. As the first contribution, the operation of MGs is considered in the networked mode under a unique beneficiary. The networked operation of the MGs reduced the costs of operating them. As the second contribution, the required reserve and self-adequacy indices are considered. According the simulation results, the proposed algorithm at the any market price, regarding the operation cost of the internal resources of the MGs and also amount of power demand required by MGs, truly calculates and proposes an optimum price to DISCO for sale energy to BMG. In this paper, the impact of considering and disregarding two important indices of MGs, that is, reserve and self-adequacy, on the profit of the DISCO in two different scenarios is investigated. In each scenario, the impact of considering two modes of MGs, that is, networked and nonnetworked, on the profit of DISCO is investigated.

In scenario 1, the reserve and self-adequacy indices are not considered for MGs. In this scenario, by comparing the simulation results, it can be found that, by operating networked of MGs, the profit of the DISCO and the cost of MGs reduced compared to nonnetworked mode at most wholesale market prices. In scenario 2, the reserve and selfadequacy indices are considered for MGs. In this scenario, by operating networked MGs, the profit of the DISCO increased compared to nonnetworked mode at most wholesale market prices. Also, the cost of MGs remained constant and even reduced in some wholesale market prices. Although the costs of networked MGs increased with considering reserve and self-adequacy indices, the network property for MGs helps them consider these indices, which are critical, not to be costly for them compared to the nonnetworked mode. 
It can be concluded that considering these indices for MGs created a trade with bidirectional benefit. In high level, the profit of DISCO increased; also, in lower level, networked MGs took advantage of the good and secure reserve and self-adequacy indices in critical situations without raising their costs.

\section{REFERENCES}

Khodaei, A. Shahidehpour, M. 2013. Microgrid-based co-optimization of generation and transmission planning in power systems. IEEE Transactions on Power Systems 28(2): 1582-1590.

Rieger, A. Thummert, R. Fridgen, G. Kahlen, M. Ketter, W. 2016. Estimating the benefits of cooperation in a residential MGs: A data driven approach. Applied Energy 180: 130-141.

Umeozor, E. C. Trifkovic, M. 2016. Operational scheduling of microgrids via parametric programming. Applied Energy 180: 672-681.

Zhang, J. Wu, Y. Guo, Y. Wang, B. Wang, H. Liu, H. 2016. A hybrid harmony search algorithm with differential evolution for day ahead scheduling problem of a micro-grid with consideration of power flow constraints. Applied Energy 183: 791-804.

Karimzadeh, K. Soleymani, S. Faghihi, F. 2019. Microgrid utilization by optimal allocation of DG units: game theory coalition formulation strategy and uncertainty in renewable energy resources. Journal of Renewable and Sustainable Energy 11(2): 025505.

Fathi, M. Bevrani, H. 2017. Regulating power management in interconnected microgrids. Journal of Renewable and Sustainable Energy 9(5): 055502.

Zhang, H. Zhao, D. Gu, Ch. Li, F. 2015. Bi-level economic operation of distribution networks with microgrid integration. Journal of Renewable and Sustainable Energy 7(2): 023420.

Bahramara, S. Parsa Moghaddam, M. Haghifam, M R. 2016. A bi level optimization model for operation of distribution networks with micro-grids. International Journal of Electrical Power and Energy Systems 82: 169-178.

Bahramara, S. Parsa Moghaddam, M. Haghifam, M R. 2015. Modeling hierarchical decision making framework for operation of active distribution grids. IET Generation, Transmission \& Distribution 9(16): 2555-2564.

Kargarian, A. Fu, Y. Dormohammadi, S. Rais-rohani, M. 2014. Optimal operation of active distribution grids: a system of systems framework. IEEE Transactions on Smart Grid 5(3): 1228-1237.

Zamora, R. Srivastava, A K. 2018. Multi-layer architecture for voltage and frequency control in networked microgrids. IEEE Transactions on Smart Grid 9: 2076-2085.

Hussain, A. Bui, V. Kim, H. 2018. A resilient and privacy-preserving energy management strategy for networked microgrids. IEEE Transaction on Smart Grid 9(3): 2127-2139.

Nikmehr, N. Najafi, S. Khodaei, A. 2017. Probabilistic optimal scheduling of networked microgrids considering time-based demand response programs under uncertainty. Applied Energy 198: 267-279.

Hussain, A. Bui, V. Kim, H. 2017. Resilience oriented optimal operation of networked hybrid microgrids. IEEE Transactions on Smart Grid.

Avirup, M. Debapriya. D. 2017. Optimal operation of microgrids using four different optimization techniques. Sustainable Energy Technologies and Assessments 21: 100-120. 
Wang, Z. Chen, B. 2015. Coordinated energy management of networked microgrids in distribution systems". IEEE Transactions on Smart Grid 6(1): 45-53.

Lei, X. Yan, X. Peng, P. Ye, T. 2013. An optimal purchase and sale power model considering microgrids". International Transactions of Electrical Energy Systems 25(2): 246-261. 